\title{
Factors Associated with Depressive Symptom in Chronic Obstructive Pulmonary Disease Based on the Third (2005) and Fourth (2008) Korea National Health and Nutritional Examination Survey (KNHANES III, IV)

\author{
Sung-Hoon Kim, Jun-Su Kim*, Jae-Young Choi, Ka-Young Lee, Tae-Jin Park, \\ Jae-Hwa Lee
}

Department of Family Medicine, Busan Paik Hospital, Inje University College of Medicine, Busan, Korea

Background: Depressive symptoms accompanied by chronic obstructive pulmonary disease (COPD) can be influenced by socioeconomic status, associated chronic diseases and the current smoking status. This study was conducted to assess factors that are associated with depressive symptoms accompanied by COPD, using the data obtained from the Korea National Health and Nutritional Survey (KNHANES) conducted in 2005 and 2008.

Methods: From the third (2005) and the fourth (2008) KNHANES, 407 (0.9\%) with physician-diagnosed COPD were selected. Of the 407 subjects, only $180(0.4 \%)$ who reported having depressive symptoms were included in this study. The associations of depressive symptoms with socioeconomic status, associated chronic diseases and smoking status were investigated.

Results: Of the total 180 subjects, 45 (25\%) had depressive symptoms. There were 102 males (55\%) and 78 females $(45 \%)$ with a slight predilection for males. In multivariate analysis, significant predictors of depressive symptoms were dependent activities of daily living (odds ratio [OR], 2.42; 95\% confidence interval [CI], 2.06 to 2.84) and association with number of chronic diseases (OR of one, two, and three, 1.40, 1.72, 2.60; 95\% CI of one, two, and three, 1.20 to $1.63,1.41$ to $2.10,1.99$ to 3.39$)$.

Conclusion: This study provides the basis for managing COPD patients in a clinical setting by understanding the number and characteristics of COPD patients with depressive symptoms. The results of this study suggest that primary physicians should manage COPD patients with consideration of risk factors for depressive symptom.

Keywords: Pulmonary Disease, Chronic Obstructive; Depression; Smoking; KNAHNES

Received: August 27, 2010, Accepted: May 16, 2011

${ }^{*}$ Corresponding Author: Jun-Su Kim

Tel: 82-51-890-6463, Fax: 82-51-894-7554

E-mail: hippoid@hanmail.net

Korean Journal of Family Medicine

Copyright (C) 2011 The Korean Academy of Family Medicine

(c) This is an open-access article distributed under the terms of the Creative Commons Attribution Non-Commercial License (http://creativecommons.org/licenses/by-nc/3.0) which permits unrestricted noncommercial use, distribution, and reproduction in any medium, provided the original work is properly cited.

\section{INTRODUCTION}

Chronic obstructive lung disease (COPD) is extremely difficult to treat successfully. It is expected to rank third among the causes of death in 2020. ${ }^{1)}$ In Korea, the prevalence of COPD has increased to $17.2 \%$ in subjects aged $\geq 45$ years. ${ }^{2}$ Since smoking is known to be the most important etiology of COPD and to affect prognosis, smoking cessation is most important in the prevention 
of COPD.

Mood disorders are frequently associated with COPD. In particular, $6 \%$ to $46 \%$ of COPD patients had associated depression. ${ }^{3,4)}$ The success of smoking cessation depends considerably on the absence or presence of associated depression, and the success rate of quitting smoking is lower in smokers with depression than in those without it. ${ }^{5)}$ Associated mood disorders may influence emotional status, physical activity and quality of life as well as clinical course and mortality. ${ }^{6-9)}$ For these reasons, knowledge of the association of depression symptom with COPD is important in the management of COPD patients. Depressive symptoms accompanied by COPD can be influenced by various factors, such as socioeconomic status, associated chronic disease and the current smoking status. ${ }^{10-14)}$ It is essential to understand factors that are associated with depressive symptoms and to maintain the effects of smoking cessation in patients with COPD.

Although there have been numerous studies on the early diagnosis, prevention and treatment of COPD, few reports have been found on the prevalence of associated depressive symptoms and therapeutic approaches to the socio-psychological aspect. ${ }^{15-19)}$ Furthermore, there have been only a few studies in Korean subjects and those who have largely been localized. ${ }^{20-22)}$ For this reason, these studies are difficult to apply in the general population.

This study was conducted to assess factors that are associated with depressive symptom accompanied by COPD, using the data obtained from the 2005 and 2008 Korea National Health and Nutritional Survey (KNHANES) and to assist for the management of depressive symptom in COPD patients.

\section{METHODS}

\section{Study Subjects}

The KNHANES has been conducted every 3 years using a probability cluster sample that is representative of Korean people in accordance with the National Health Promotion Law legislated in 1995. The first KNHANES was conducted in 1998, the second in 2001, the third in 2005 and the fourth in 2008.

The number of subjects who responded to the third (2005) and the fourth (2008) KNHANES was 43,889 in total. Of the 43,889 subjects, 407 (0.9\%) who reported being diagnosed with
COPD by physicians were selected. Of the 407 subjects, only 180 ( $0.4 \%)$ who reported having depressive symptom were included in this study.

\section{Methods}

As for depressive symptom, subjects were asked to answer the question, "Have you felt sad or desperate for $\geq 2$ weeks during the past 1 year so as to disturb everyday life?" Subjects who reported "yes" were regarded as having depressive symptom. Subjects were asked to report their smoking status as one of the following: current smoking, past smoking and others. Subjects who reported "current smoking" were regarded as current smokers. Current and past smokers were asked to report their smoking amounts as follows: $<10$ cigarettes per day and $\geq 10$ cigarettes per day. Their intention of smoking cessation was assessed in terms of time point: "within 1 month," "within 6 months," "not decided" and "no intention." Their experience with smoking cessation campaigns was assessed. Socio-demographic factors, including age, sex, marital status, educational level and household income, were assessed. The subjects were divided into 3 groups: the $\leq$ $64,65-74$, and $\geq 75$ age groups. Marital status was reported as "married," "unmarried," "separated," "widowed” and "divorced," and it was grouped as "living with a spouse" and "others." The educational level was reported as either $\geq$ high school or $<$ high school. Household income was reported as lower (within the first and second quartiles) and higher (within the third and fourth quartiles). Perceived health was reported as "very good," "good," "moderate," "bad," or "very bad," and then it was grouped as "very good/good/moderate" and "bad/very bad." As for the activities of daily living $(\mathrm{ADL})$, no disturbances in everyday life were defined when subjects answered " $n$ " to the question "Do you have any disturbances in everyday life?” Chronic diseases included stroke, hypertension, diabetes mellitus, ischemic heart disease, liver cirrhosis, arthritis, asthma and chronic renal failure, which were selected as main diseases in the 2005 and 2008 KNHANES. Subjects with one or more cancers in the stomach, liver, lung, colon, cervix or breast were defined as 'major cancer' subjects, which were based on the answer " $y$ " to the question "Were you diagnosed with cancer(s) by a physician?" in order to avoid bias generated by subjective assessment. Subjects with a body mass index (BMI) of $<18.5$ were classified as underweight, those with a BMI of 18.5-24.9 as normal weight, and those with a BMI of 25 
as obese.

\section{Statistical Analysis}

Statistical analyses were performed using SPSS ver. 17.0 (SPSS Inc., Chicago, IL, USA). A P-value of $<0.05$ was considered statistically significant. The distribution of variables in subject groups with and without depressive symptom was assessed using the chi-square test, and differences in variables were examined using the chi-square test and Fischer's exact test. Each frequency was calculated by adding weighted values (variable with weighted values, wt_itv). In multivariate analysis, factors associated with depressive symptom were examined. Independent risk factors were investigated by logistic regression analysis. In model 1 , variables were analyzed without any adjustment, while in model 2 , variables were analyzed after adjustment for sex, age, household income, educational level and current smoking status. All analyses were performed by reflecting weighted values at the stratification of the samples applied to the KNHANEs.

\section{RESULTS}

\section{Socio-Demographic Characteristics of Sub- jects (Table 1) \\ Of the total 180 subjects, 45 (25\%) had depressive symptom.} There were 102 males (55\%) and 78 females (45\%) with slight predilection for males. There were 116 subjects $(66.3 \%)$ in the $\leq 64$ age group, 40 subjects $(20.1 \%)$ in the $65-74$ age group, and $24(13.6 \%)$ in the $\geq 75$ age group. Subjects with a spouse accounted for 116 (68.4\%) of all subjects. Subjects with < middle school education accounted for 116 (58.1\%) of all subjects. Subjects with lower income accounted for 113 (60.7\%) of all subjects. There were no significant differences in perceived health between subjects in good health status and those who were not. Disturbances in everyday life were more common in the independent group than in the dependent group. The number of associated chronic disease was none in 71 subjects (42.2\%), 1 in 60 subjects (30.3\%), 2 in 26 subjects (17.0\%), and $\geq 3$ in 23 subjects (10.5\%). Main cancers were observed in 7 subjects (3.0\%). As assessed by BMI, 36 subjects (16.2\%) were obese, 105 subjects (75.3\%) were normal weight, and 8 subjects ( $8.5 \%)$ were underweight. The number of current smokers was 47 (22.8\%).
Table 1. General characteristics of study subjects.

\begin{tabular}{|c|c|c|c|}
\hline \multicolumn{2}{|c|}{ Characteristics } & \multirow{2}{*}{$\begin{array}{c}\text { Total }(\mathrm{n}=180) \\
\text { No. }(\%)^{*} \\
102(55.0)\end{array}$} & \multirow{2}{*}{$\begin{array}{c}\begin{array}{c}\text { Standard } \\
\text { error (\%) }\end{array} \\
3.5\end{array}$} \\
\hline Sex & Male & & \\
\hline & Female & $78(45.0)$ & 3.5 \\
\hline \multirow[t]{3}{*}{ Age } & $\leq 64$ & $116(66.3)$ & 3.1 \\
\hline & $65-74$ & $40(20.1)$ & 2.6 \\
\hline & $\geq 75$ & 24 (13.6) & 2.6 \\
\hline \multirow[t]{2}{*}{ Living with a spouse } & Yes & 135 (68.4) & 3.3 \\
\hline & No & 45 (31.6) & 3.3 \\
\hline \multirow[t]{2}{*}{ Education } & $\geq$ High school & 64 (41.9) & 4.4 \\
\hline & $\leq$ Middle school & $116(58.1)$ & 4.4 \\
\hline \multirow[t]{2}{*}{ Income } & Lower & $113(60.7)$ & 4.3 \\
\hline & Higher & $63(39.3)$ & 4.3 \\
\hline \multirow[t]{3}{*}{ Perceived health } & Not available & $4(2.2)$ & \\
\hline & Good & $92(50.3)$ & 3.4 \\
\hline & Not good & $88(49.7)$ & 3.4 \\
\hline \multirow[t]{2}{*}{ Activities of daily living } & Independent & $139(76.7)$ & 3.2 \\
\hline & Dependent & $41(23.3)$ & 3.2 \\
\hline \multirow[t]{4}{*}{ No.of chronic disease $^{\dagger}$} & 0 & $71(42.2)$ & 3.5 \\
\hline & 1 & $60(30.3)$ & 2.9 \\
\hline & 2 & $26(17.0)$ & 1.9 \\
\hline & $\geq 3$ & 23 (10.5) & 2.8 \\
\hline \multirow[t]{2}{*}{ Major cancer ${ }^{\ddagger}$} & No & $173(97.0)$ & 1.0 \\
\hline & Yes & $7(3.0)$ & 1.0 \\
\hline \multirow[t]{3}{*}{ Body mass index ${ }^{\S}$} & Obese & 36 (16.2) & 4.1 \\
\hline & Normal weight & $105(75.3)$ & 4.4 \\
\hline & Underweight & $8(8.5)$ & 2.9 \\
\hline \multirow[t]{3}{*}{ Current smoking status } & Not available & 31 (17.2) & \\
\hline & Current smoker & $47(22.8)$ & 2.6 \\
\hline & $\begin{array}{l}\text { No current } \\
\text { smoker }\end{array}$ & $133(77.2)$ & 2.6 \\
\hline
\end{tabular}

*Weighted percent. ${ }^{\dagger}$ Chronic disease: stroke, hypertension, diabetes, ischemic heart disease, liver cirrhosis, arthritis, asthma and chronic renal failure. ${ }^{\ddagger}$ Major cancer: stomach, liver, lung, cervix, breast and colon cancers. ${ }^{\S} \mathrm{BMI}$ : obese, $\geq 25$; normal weight, 18.5 -24.9 ; underweight, $<18.5$. 
Table 2. Depressive symptom according to socio-demographic characteristics, chronic disease and smoking status in study subjects.

\begin{tabular}{|c|c|c|c|c|c|c|}
\hline \multirow{3}{*}{ Variable } & \multirow{3}{*}{ Total no. } & \multicolumn{4}{|c|}{ Depressive symptom } & \multirow{3}{*}{ P-value } \\
\hline & & \multicolumn{2}{|c|}{ Yes } & \multicolumn{2}{|c|}{ No } & \\
\hline & & No. $(\%)^{*}$ & SE (\%) & No. $(\%)^{*}$ & SE (\%) & \\
\hline \multicolumn{7}{|l|}{ Sociodemographic } \\
\hline Sex & 180 & & & & & 0.03 \\
\hline Male & & $20(14.4)$ & 3.6 & $82(85.6)$ & 3.6 & \\
\hline Female & & $25(36.0)$ & 8.1 & $53(64.0)$ & 8.1 & \\
\hline Age & 180 & & & & & 0.91 \\
\hline$\leq 64$ & & $31(24.3)$ & 4.2 & $85(75.7)$ & 4.2 & \\
\hline $65-74$ & & $10(22.6)$ & 8.2 & $30(77.4)$ & 8.2 & \\
\hline$\geq 75$ & & $4(27.9)$ & 17.4 & $20(72.1)$ & 17.4 & \\
\hline Married & 180 & & & & & 0.14 \\
\hline Yes & & $31(19.4)$ & 3.2 & $104(80.6)$ & 3.2 & \\
\hline No & & $14(38.2)$ & 13.0 & $31(61.8)$ & 13.0 & \\
\hline Education & 180 & & & & & 0.30 \\
\hline$\geq$ High school & & $16(20.6)$ & 3.9 & $48(79.4)$ & 3.9 & \\
\hline$\leq$ Middle school & & $29(27.2)$ & 5.9 & 87 (72.8) & 5.9 & \\
\hline Income & 176 & & & & & 0.55 \\
\hline Lower & & $31(23.4)$ & 3.5 & $82(76.6)$ & 3.5 & \\
\hline Higher & & $12(19.3)$ & 5.7 & $51(80.7)$ & 5.7 & \\
\hline Perceived health & 180 & & & & & 0.44 \\
\hline Good & & $20(20.6)$ & 5.4 & $72(79.4)$ & 5.4 & \\
\hline Not good & & $25(29.0)$ & 8.1 & $63(71.0)$ & 8.1 & \\
\hline Activities of daily living & 180 & & & & & 0.005 \\
\hline Independent & & $27(16.4)$ & 3.6 & $112(83.6)$ & 3.6 & \\
\hline Dependent & & $18(52.0)$ & 12.1 & $23(48.0)$ & 12.1 & \\
\hline No. of chronic disease ${ }^{\dagger}$ & 180 & & & & & 0.02 \\
\hline 0 & & $16(21.7)$ & 5.8 & $55(78.3)$ & 5.8 & \\
\hline 1 & & $13(20.9)$ & 5.0 & $47(79.1)$ & 5.0 & \\
\hline 2 & & $4(11.0)$ & 6.7 & $22(89.0)$ & 6.7 & \\
\hline$\geq 3$ & & $12(60.4)$ & 17.2 & $11(39.6)$ & 17.2 & \\
\hline Major cancer $^{\ddagger}$ & 180 & & & & & 0.10 \\
\hline No & & $44(25.2)$ & 4.1 & $129(74.8)$ & 4.1 & \\
\hline Yes & & $1(6.1)$ & 6.3 & $6(93.9)$ & 6.3 & \\
\hline Body mass index ${ }^{\S}$ & 149 & & & & & 0.25 \\
\hline Obese & & $8(20.9)$ & 6.8 & $28(79.1)$ & 6.8 & \\
\hline Normal weight & & $27(23.8)$ & 5.7 & 78 (76.2) & 5.7 & \\
\hline Underweight & & $3(53.1)$ & 22.8 & $5(46.9)$ & 22.8 & \\
\hline \multicolumn{7}{|l|}{ Chronic disease } \\
\hline Stroke & 180 & & & & & 0.001 \\
\hline No & & $43(13.2)$ & 13.3 & $133(86.8)$ & 13.3 & \\
\hline Yes & & $2(21.9)$ & 2.9 & $2(78.1)$ & 2.9 & \\
\hline Hypertension & 180 & & & & & 0.72 \\
\hline No & & $31(30.6)$ & 12.7 & $102(69.4)$ & 12.7 & \\
\hline Yes & & $14(23.0)$ & 4.3 & $33(77.0)$ & 4.3 & \\
\hline
\end{tabular}


Table 2. Continued.

\begin{tabular}{|c|c|c|c|c|c|c|}
\hline \multirow{3}{*}{ Variable } & \multirow{3}{*}{ Total no. } & \multicolumn{4}{|c|}{ Depressive symptom } & \multirow{3}{*}{ P-value } \\
\hline & & \multicolumn{2}{|c|}{ Yes } & \multicolumn{2}{|c|}{ No } & \\
\hline & & No. $(\%)^{*}$ & SE (\%) & No. $(\%)^{*}$ & SE (\%) & \\
\hline Diabetes & 180 & & & & & 0.64 \\
\hline No & & 38 (19.7) & 8.9 & $125(80.3)$ & 8.9 & \\
\hline Yes & & $7(25.1)$ & 4.7 & 10 (74.9) & 4.7 & \\
\hline Ischemic heart disease & 180 & & & & & 0.11 \\
\hline No & & 39 (58.6) & 48.5 & $129(41.4)$ & 48.5 & \\
\hline Yes & & $6(54.9)$ & 22.5 & $6(45.1)$ & 22.5 & \\
\hline Liver cirrhosis & 180 & & & & & NA \\
\hline No & & $45(24.7)$ & 4.1 & $135(75.3)$ & 4.1 & \\
\hline Yes & & 0 & & 0 & & \\
\hline Arthritis & 180 & & & & & 0.004 \\
\hline No & & $26(6.8)$ & 7.2 & $101(93.2)$ & 7.2 & \\
\hline Yes & & $19(53.1)$ & 11.3 & $34(46.9)$ & 11.3 & \\
\hline Asthma & 180 & & & & & 0.36 \\
\hline No & & $38(25.9)$ & 4.8 & $109(74.1)$ & 4.8 & \\
\hline Yes & & $7(17.0)$ & 7.0 & $26(83.0)$ & 7.0 & \\
\hline Chronic renal failure & 180 & & & & & 0.90 \\
\hline No & & $43(24.6)$ & 4.2 & $130(75.4)$ & 4.2 & \\
\hline Yes & & $2(23.0)$ & 10.9 & $5(77.0)$ & 10.9 & \\
\hline \multicolumn{7}{|l|}{ Smoking status } \\
\hline Smoking & 180 & & & & & 0.36 \\
\hline Current smoking & & $12(32.6)$ & 9.6 & $35(67.4)$ & 9.6 & \\
\hline No current smoking & & $33(22.2)$ & 5.2 & $100(77.8)$ & 5.2 & \\
\hline Mean smoking per day in current smokers & 47 & & & & & 0.13 \\
\hline$\geq 10$ cigarettes & & $10(25.2)$ & 7.2 & $31(74.8)$ & 7.2 & \\
\hline$<10$ cigarettes & & $2(36.9)$ & 23.7 & $4(63.1)$ & 23.7 & \\
\hline Intention of smoking cessation in current smokers & 47 & & & & & 0.42 \\
\hline In $1 \mathrm{mo}$ & & $3(42.9)$ & 29.3 & $4(47.1)$ & 29.3 & \\
\hline In 6 mo & & $0(0.0)$ & 0 & $6(100.0)$ & 0 & \\
\hline At some time & & $5(26.3)$ & 18.1 & $14(73.7)$ & 18.1 & \\
\hline No intention & & $4(26.7)$ & 13.2 & $11(73.3)$ & 13.2 & \\
\hline Mean smoking amount per day in past smokers & 49 & & & & & 0.74 \\
\hline$\geq 10$ cigarettes & & $7(16.7)$ & 8.4 & $35(83.3)$ & 8.4 & \\
\hline$<10$ cigarettes & & $2(28.6)$ & 14.3 & $5(71.4)$ & 14.3 & \\
\hline Experience of smoking cessation campaigns & 166 & & & & & 0.65 \\
\hline Yes & & $41(23.6)$ & 3.4 & $119(76.4)$ & 3.4 & \\
\hline No & & $1(15.3)$ & 14.7 & $5(84.7)$ & 14.7 & \\
\hline
\end{tabular}

NA: not applicable.

*Weighted percent. ${ }^{\dagger}$ Chronic disease: stroke, hypertension, diabetes, ischemic heart disease, liver cirrhosis, arthritis, asthma and chronic renal failure. ${ }^{\ddagger}$ Major cancer: stomach, liver, lung, cervix, breast, colon cancer. ${ }^{\circledR}$ BMI: obese, $\geq 25$; normal weight, 18.5-24.9; underweight, $<18.5$. 


\section{Comparison of Characteristics according to Depressive Symptom (Table 2)}

Depressive symptom tended to occur more frequently in females with statistical significance. Depressive symptom was not significantly associated with age, the presence of a spouse, educational level, household income level or perceived health. The prevalence of depressive symptom was significantly higher in subjects with dependent ADL than in those with independent ADL. Depressive symptom occurred more frequently in subjects with associated chronic diseases. The presence of $\geq 3$ main cancers was not significantly associated with the risk for depressive symptom. BMI tended to be more frequently associated with depressive symptom, but without any statistical significance. As for chronic disease, ischemic heart disease, hypertension, diabetes mellitus, asthma and chronic renal failure were not significantly associated with depressive symptom, whereas stroke and arthritis were significantly associated with depressive symptom. Depressive symptom was not associated with current smoking, mean smoking amount, intention of smoking cessation or experience with smoking cessation campaigns.

\section{Predictors of Depressive Symptoms (Table 3)} In multivariate analysis, dependent $\mathrm{ADL}$ (OR, 2.42; 95\% CI, 2.06 to 2.84 ) and association with the number of chronic diseases (OR of one, two, and three, 1.40, 1.72, 2.60; 95\% CI of one, two, and three, 1.20-1.63,1.41-2.10,1.99-3.39) were still significant predictors even after adjustment.

\section{DISCUSSION}

In this study of COPD patients in the general Korean population, dependent $\mathrm{ADL}$ and association with chronic diseases were the significant predictors of depressive symptom, which corresponds well with the result of the earlier study conducted by Ng et al. ${ }^{12)}$ The odds ratio continued to be significant after adjustment for sex, age, household income level and current smoking. Depressive symptom was significantly associated with the number of comorbid chronic diseases, and the odds ratio continued to be significant after adjustment for variables. Jung et al. $^{23)}$ have reported that there is a positive relationship between the number of comorbid chronic diseases and dependent ADL. Based on these results and ours, it is conceivable that dependent $\mathrm{ADL}$ may be indirectly associated with depressive symptom.

Table 3. Riskfactors for depressive symptom: adjusted odds ratios from a multivariate logistic regression model.

\begin{tabular}{|c|c|c|c|c|c|}
\hline \multicolumn{2}{|c|}{ Factors } & \multicolumn{2}{|c|}{ Model 1* } & \multicolumn{2}{|c|}{ Model $2^{\dagger}$} \\
\hline & & $\mathrm{OR}^{\ddagger}$ & $95 \% \mathrm{CI}^{\ddagger}$ & $\mathrm{OR}^{\ddagger}$ & $95 \% \mathrm{CI}^{\ddagger}$ \\
\hline \multirow[t]{2}{*}{ Activities of daily living } & Independent & Reference & & Reference & \\
\hline & Dependent & 2.94 & $2.54-3.42$ & 2.42 & $2.06-2.84$ \\
\hline \multirow[t]{4}{*}{ No. of chronic disease ${ }^{\S}$} & 0 & Reference & & Reference & \\
\hline & 1 & 1.48 & $1.28-1.71$ & 1.40 & $1.20-1.63$ \\
\hline & 2 & 2.13 & $1.77-2.57$ & 1.72 & $1.41-2.10$ \\
\hline & $\geq 3$ & 3.35 & $2.61-4.30$ & 2.60 & $1.99-3.39$ \\
\hline \multirow[t]{2}{*}{ Stroke } & No & Reference & & Reference & \\
\hline & Yes & 0.36 & $0.08-1.64$ & 0.47 & $0.11-2.03$ \\
\hline \multirow[t]{2}{*}{ Arthritis } & No & Reference & & Reference & \\
\hline & Yes & 0.98 & $0.74-1.30$ & 0.84 & $0.64-1.11$ \\
\hline
\end{tabular}

${ }^{*}$ Model 1: Crude odds ratio. ${ }^{\dagger}$ Model 2: Adjustment for sex, age, economic status and current smoking status. ${ }^{\ddagger}$ Odds ratio (OR) and $95 \%$ confidence interval (CI) were estimated after adjustment using sample weights and survey year. ${ }^{\S}$ Chronic disease: stroke, hypertension, diabetes, ischemic heart disease, liver cirrhosis, arthritis, asthma and chronic renal failure. 
Some studies have demonstrated that there are significant associations of depressive symptoms with sex, age, educational level, household income level or BMI, whereas others have not. ${ }^{11-14,24,25)}$ Compared to previous studies, depressive symptom in our study tended to increase without any statistical significance, probably due to a relatively small sample size as well as to differences in study subjects and assessment tools between previous studies and ours.

It is well known that chronic diseases are closely associated with depressive symptoms. In our study, comorbid stroke and arthritis were significantly associated with depressive symptoms in univariate analysis but not in multivariate analysis after adjustment for variables. Schane et al. ${ }^{13)}$ have indicated that depressive symptoms are significantly associated with diabetes mellitus and arthritis, whereas Chavannes et al. ${ }^{14)}$ have reported that the reverse is true. Further studies are needed to confirm these results.

In our study, it was found that depressive symptom was not significantly associated with current smoking status. Although it is unclear whether smoking induces depressive symptoms or whether depressive symptoms induce smoking, a positive association between smoking and depressive symptoms is well known. ${ }^{13,26,27)}$ In addition, it is important to determine whether there is a positive association between depressive symptoms and smoking amounts in COPD patients. ${ }^{28)}$ Some previous studies have pointed out that depressive symptoms are not significantly associated with current smoking. ${ }^{12,14)}$ Based on the results of these studies and ours, it is thought that depressive symptoms are less strongly associated with smoking in COPD patients than in the general population. The differences in such associations between the previous studies and ours may be because 1) the subjects of our study were restricted to COPD patients, 2) the number of study subjects was relatively small, and 3) the definition of depressive symptoms of previous studies was different. Depressive symptom was not significantly associated with smoking amounts, intention of smoking cessation or experience with smoking cessation campaigns.

The results of this study are subjected to some limitations. First, because this was a cross-sectional study, there is a limit to interpretations of a cause-and-effect relationship between depressive symptoms and related variables. Second, because we analyzed data obtained from the 2005 and 2008 surveys which were conducted according to different criteria, the prevalence or incidence of COPD in either 2005 or 2008 may not have been accurately investigated. However, in multivariate analysis, we attempted to minimize the difference in prevalence or incidence of COPD by using dummy variables. Third, depressive symptoms were assessed by using the answer to a single question "Have you felt sad or desperate continuously for $\geq 2$ weeks so as to disturb your everyday life?" Watkins et al. ${ }^{29)}$ investigated the accuracy of a single question "Do you often sad or depressed?" in screening for depression in a cohort of patients after strokes and reported a sensitivity of $86 \%$, a specificity of $78 \%$, a positive predictability of $82 \%$ and a negative predictability of $82 \%$. Fourth, the incidence of physician-diagnosed chronic disease adopted in our study seemed to be lower than the actual incidence. Furthermore, because we did not determine whether the chronic diseases were in an active state or not, their association with depressive symptoms seemed to be insignificant. Fifth limitation is that these results might not be representative of Korean COPD patients. In this study two different sample weights were used for the reflection of each yearly stratified sampling. Because integrative sample weight of two-year data set was not developed. Finally, the number of current smokers was only 47, which was insufficient to investigate the differences in depressive symptoms according to current smoking status or intention of smoking cessation.

This study provides the basis for managing COPD patients in a clinical setting by understanding the number and characteristics of COPD patients with depressive symptoms. The results of this study suggest that primary physicians should manage COPD patients in consideration of risk factors for depressive symptoms and recommend that they stop smoking, regardless of the presence of depressive symptoms. Additional controlled studies are warranted.

\section{ACKNOWLEDGEMENTS}

This work was supported by Grant from Inje University, 2009.

\section{REFERENCES}

1. Murray CJ, Lopez AD. Alternative projections of mortality 
and disability by cause 1990-2020: Global Burden of Disease Study. Lancet 1997;349:1498-504.

2. Kim DS, Kim YS, Jung KS, Chang JH, Lim CM, Lee JH, et al. Prevalence of chronic obstructive pulmonary disease in Korea: a population-based spirometry survey. Am J Respir Crit Care Med 2005; 172:842-7.

3. Curtis JR, Patrick DL. The assessment of health status among patients with COPD. Eur Respir J Suppl 2003;41:36s-45s.

4. Hynninen KM, Breitve MH, Wiborg AB, Pallesen S, Nordhus IH. Psychological characteristics of patients with chronic obstructive pulmonary disease: a review. J Psychosom Res 2005;59:429-43.

5. Glassman AH, Helzer JE, Covey LS, Cottler LB, Stetner F, Tipp JE, et al. Smoking, smoking cessation, and major depression. JAMA 1990;264:1546-9.

6. Dahlen I, Janson C. Anxiety and depression are related to the outcome of emergency treatment in patients with obstructive pulmonary disease. Chest 2002;122:1633-7.

7. Gudmundsson G, Gislason T, Janson C, Lindberg E, Hallin $\mathrm{R}$, Ulrik CS, et al. Risk factors for rehospitalisation in COPD: role of health status, anxiety and depression. Eur Respir J 2005;26:414-9.

8. Crockett AJ, Cranston JM, Moss JR, Alpers JH. The impact of anxiety, depression and living alone in chronic obstructive pulmonary disease. Qual Life Res 2002;11:309-16.

9. Stage KB, Middelboe T, Pisinger C. Depression and chronic obstructive pulmonary disease (COPD): impact on survival. Acta Psychiatr Scand 2005;111:320-3.

10. Wagena EJ, Kant I, Huibers MJ, van Amelsvoort LG, Swaen GM, Wouters EF, et al. Psychological distress and depressed mood in employees with asthma, chronic bronchitis or emphysema: a population-based observational study on prevalence and the relationship with smoking cigarettes. Eur J Epidemiol 2004;19:147-53.

11. Lin M, Chen Y, McDowell I. Increased risk of depression in COPD patients with higher education and income. Chron Respir Dis 2005;2:13-9.

12. Ng TP, Niti M, Fones C, Yap KB, Tan WC. Co-morbid association of depression and COPD: a population-based study. Respir Med 2009; 103:895-901.

13. Schane RE, Walter LC, Dinno A, Covinsky KE, Woodruff PG. Prevalence and risk factors for depressive symptoms in persons with chronic obstructive pulmonary disease. J Gen Intern Med 2008;23:1757-62.

14. Chavannes NH, Huibers MJ, Schermer TR, Hendriks A, van Weel C, Wouters EF, et al. Associations of depressive symptoms with gender, body mass index and dyspnea in primary care COPD patients. Fam Pract 2005;22:604-7.

15. Light RW, Merrill EJ, Despars JA, Gordon GH, Mutalipassi LR. Prevalence of depression and anxiety in patients with COPD: relationship to functional capacity. Chest 1985; $87: 35-8$.

16. Kunik ME, Roundy K, Veazey C, Souchek J, Richardson P, Wray NP, et al. Surprisingly high prevalence of anxiety and depression in chronic breathing disorders. Chest 2005; 127:1205-11.

17. Wagena EJ, Arrindell WA, Wouters EF, van Schayck CP. Are patients with COPD psychologically distressed? Eur Respir J 2005;26:242-8.

18. van Ede L, Yzermans CJ, Brouwer HJ. Prevalence of depression in patients with chronic obstructive pulmonary disease: a systematic review. Thorax 1999;54:688-92.

19. Borson S, Claypoole K, McDonald GJ. Depression and chronic obstructive pulmonary disease: treatment trials. Semin Clin Neuropsychiatry 1998;3:115-30.

20. Chung KH, Kim JH, Hah ES, Kim SJ, Lee KJ, Lee SH, et al. Frequency and clinical characteristics of depression and anxiety disorder in COPD patients. Tuberc Respir Dis 2005;59 Suppl 2:62.

21. Ryu YJ, Chun EM, Sim YS, Lee JH. Depression and anxiety in outpatients with chronic obstructive pulmonary disease. Tuberc Respir Dis 2007;62:11-8.

22. Chin HJ, Lee KH, Park CS, Son CW, Lee HY, Yu SK, et al. Prevalence and risk factors of depression in patients with chronic obstructive pulmonary disease. Tuberc Respir Dis 2008;65:191-7.

23. Jung JY, Kim JS, Choi HJ, Lee KY, Park TJ. Factors Associated with ADL and IADL from the Third Korea National Health and Nutrition Examination Survey (KNHANES III), 2005. Korean J Fam Med 2009;30:598-609.

24. Di Marco F, Verga M, Reggente M, Maria Casanova F, Santus P, Blasi F, et al. Anxiety and depression in COPD patients: The roles of gender and disease severity. Respir Med 2006;100:1767-74. 
25. Laurin C, Lavoie KL, Bacon SL, Dupuis G, Lacoste G, Cartier A, et al. Sex differences in the prevalence of psychiatric disorders and psychological distress in patients with COPD. Chest 2007; 132:148-55.

26. Ng TP, Niti M, Tan WC, Cao Z, Ong KC, Eng P. Depressive symptoms and chronic obstructive pulmonary disease: effect on mortality, hospital readmission, symptom burden, functional status, and quality of life. Arch Intern Med 2007; 167:60-7.
27. Munafo MR, Araya R. Cigarette smoking and depression: a question of causation. Br J Psychiatry 2010;196:425-6.

28. Glassman AH, Covey LS, Stetner F, Rivelli S. Smoking cessation and the course of major depression: a follow-up study. Lancet 2001;357:1929-32.

29. Watkins C, Daniels L, Jack C, Dickinson H, van Den Broek M. Accuracy of a single question in screening for depression in a cohort of patients after stroke: comparative study. BMJ 2001;323:1159. 